\title{
UJI TOKSISITAS DAN IDENTIFIKASI SENYAWA EKSTRAK ALGA MERAH (Eucheuma cottonii) TERHADAP LARVA UDANG Artemia salina LEACH
}

\author{
Noer Mardlatillah Sharo, Rachmawati Ningsih, A. Nasichuddin, Ahmad Hanapi \\ Jurusan Kimia, Fakultas Sains dan Teknologi UIN Maulana Malik Ibrahim Malang \\ Corresponding author: 1414_scorpio@yahoo.com
}

\begin{abstract}
Eucheuma cottonii is a multicellular algae (multicellular) that have bioactive compounds used in medicine, such as anticancer. The purpose of this research is to know the level of toxicity of the crude extract of ethanol and n-hexane red algae (Eucheuma cottonii) against larvae of shrimp A. salina Leach and to know the active compounds contained in crude extracts of ethanol and n-hexane red algae (Eucheuma cottonii).

This research was conducted with the maceration extraction continuing by test toxicity against the shrimp larvae of A. salina Leach (BSLT). The result of the toxicity test then proceeds with the test reagents and phytochemicals with thin layer chromatography for positive test of compound phytochemicals. Thin-layer chromatography using eluen n-hexane: ethyl acetate (7:3) to ethanol extract and n-hexane: ethyl acetate (17: 3) for $n$-hexane extract. Data on toxicity of A. salina Leach analyzed by probit analysis to find out the value of $\mathrm{LC}_{50}$ on each extract.

The results of this research indicate that each of the rough red algae extract (Eucheuma cottonii) by using a solvent of ethanol and n-hexane have toxicity values $\left(\mathrm{LC}_{50}\right)$ of shrimp larvae of $A$. salina Leach consecutive $58,0128 \mathrm{ppm}$ and 61,7571 ppm. Active compounds content of Phytochemical test results i.e. triterpenoid (ethanol extract) and steroids (n-hexsane extract). The TLC triterpenoid obtained 7 stains, and the results obtained steroids 8 TLC stains.
\end{abstract}

Keywords: red algae (Eucheuma cottonii), toxicity test, Artemiasalina Leach, phytochemicals test, a thin Layer Chromatography (TLC).

\section{ABSTRAK}

Eucheuma cottonii merupakan alga multiseluler (bersel banyak) yang memiliki senyawa bioaktif yang digunakandalamduniapengobatan, misalnyasebagaiantikanker. Tujuan dari penelitian ini adalah untuk mengetahui tingkat toksisitas ekstrak kasar etanol dan $n$-heksana alga merah (Eucheuma cottonii) terhadap larva udang A. salina Leachdan untuk mengetahui golongan senyawa aktif yang terkandung dalam ekstrak kasar etanol dan $n$-heksana alga merah (Eucheuma cottonii).

Penelitian ini dilakukan dengan ekstraksi maserasi dilanjutkan dengan uji toksisitas terhadap larva udang A.salinaLeach (BSLT). Hasil dari uji toksisitas kemudian dilanjutkan dengan uji fitokimia dengan reagen dan kromatografi lapis tipis untuk senyawa yang positif dari uji fitokimia. Kromatografi lapis tipis menggunakan eluen $n$-heksana:etil asetat (7:3) untuk ekstrak etanol dan $n$-heksana:etil asetat (17:3) untuk ekstrak $n$-heksana. Data toksisitasA.salinaLeach dianalisis dengan analisis probit untuk mengetahui nilai LC50 pada masing-masing ekstrak.

Hasil dari penelitian ini menunjukkan bahwa masing-masing ekstrak kasar alga merah (Eucheuma cottonii) dengan menggunakan pelarut etanol dan $n$-heksana memiliki nilai toksisitas $\left(\mathrm{LC}_{50}\right)$ terhadap larva udang A. salina Leach berturut-turut yaitu 58,0128 ppm dan 61,7571 ppm. Kandungan senyawa aktif hasil uji fitokimia yaitu triterpenoid (ekstrak etanol) dan steroid (ekstrak $n$-heksana). Hasil KLT triterpenoid diperoleh 7 noda, dan hasil KLT steroid diperoleh 8 noda.

Kata Kunci : Alga merah (Eucheuma cottonii), uji toksisitas, Artemia salina Leach, uji fitokimia, Kromatografi Lapis Tipis (KLT).

\section{PENDAHULUAN}

Indonesia adalah negara kepulauan terbesar di dunia. Perairan laut yang luas membentang, menghubungkan pulau-pulau tersebut. Panjang pantai $81.000 \mathrm{Km}$ atau14\% garis pantai seluruh dunia, di mana 2/3 wilayah Indonesia berupa perairan laut.Salah satu sumber daya hayati yang cukup potensial dari perairan laut Indonesia adalah rumput laut dengan 
berbagai macam jenisnya. Penyebaran rumput laut terdapat hampir di seluruh perairan Indonesia. Budidaya rumput laut telah dilaksanakan, antara lain di Pulau Lombok, Nusa Tenggara Barat (NTB) dan di Pulau-pulau Jawa dan Madura. Rumput laut merupakan bagian dari tanaman perairan, yang termasuk pada kelas makro alga (Costa, 2003).

Alga adalah biota laut yang umumnya tumbuh melekat pada substrat tertentu. Alga merah merupakan kelompok alga yang jenis-jenisnya memiliki berbagai bentuk dan variasi warna. Alga merah Eucheumacottoni iini banyak dibudidayakan oleh masyarakat Indonesia. Salah satud aerah yang membudidayakan Eucheuma cottonii adalah di Pantai Jumiang. Pantai ini terletak di Dusun Jumiang, Desa Tanjung, Kecamatan Pademawu, Kabupaten Pamekasan. Alga di pantai ini hanya dibudidayakan oleh masyarakat sekitar, tetapi hampir seluruh hasil produksinya yang jumlahnya mencapai puluhan ton pertahun di ekspor dan sebagian besar dijadikan bahan makanan (Nurhayati dkk, 2006). Penelitian ini adalah untuk mencari manfaat lain dari makro alga Eucheuma cottonii terutama di bidang pengobatan sebagai senyawa antimikroba, antikanker dan pestisida.

Tujuan dari penelitian ini adalah untuk mengetahui tingkat toksisitas ekstrak kasar etanol dan $n$-heksana alga merah (Eucheuma cottonii) terhadap larva udang A. salina Leachdan untuk mengetahui golongan senyawa aktif yang terkandung dalam ekstrak kasar etanol dan $n$-heksana alga merah (Eucheuma cottonii).

\section{METODE PENELITIAN \\ ALAT DAN BAHAN}

Alat yang digunakanadalah pisau, neraca analitik, cawan penguap, oven,desikator kaca vakum,nampan, blender, spatula, erlenmeyer $500 \mathrm{~mL}$, aluminium foil, kertassaring, rotary evaporator, botolvial, kaca arloji, aerator, labuukur $10 \mathrm{~mL}$, pipet ukurmikro, pipet tetes, sonikasi, gelaskimia,tabungreaksi, raktabungreaksi, plat silika $\mathrm{GF}_{254}$, gelaskimia $50 \mathrm{~mL}$, bejanapengembang, pipakapilerdanlampu UV.

Bahan yang digunakan adalah Eucheuma cottonii, telur larva udang Artemiasalina Leach, larutan ragi roti, dan air laut.

Sedangkan bahan kimia yang digunakan adalah etanol $96 \%, n$-heksana, DMSO, asam klorida $2 \%$, metanol $50 \%$, kloroform, asam asetat, asam sulfat pekat, logam $\mathrm{Mg}$, asam klorida pekat, reagenDragendorf, reagenMayer, metanol, amoniak pekat, butanol, etil asetat, aquades, sikloheksana dan pereaksi LiebermannBurchard.

\section{PROSEDUR PENELITIAN Preparasi Sampel}

Alga merah Eucheuma cottoniisegar dicuci, dilakukan proses pengeringan dengan cara penjemuran. Setelah kering alga merah dihaluskan dengan cara digiling, kemudian diayak dengan ayakan 60 mesh.

\section{Analisis Kadar Air}

Sebanyak 5 gram serbuk sampel pada cawan konstan dipanaskan dalam oven pada suhu $100-105{ }^{0} \mathrm{C}$ sekitar 15 menit. Cawan disimpan dalam desikator sekitar 10 menit selanjutnya ditimbang. Dilakukan pengulangan sampai di peroleh berat konstan. Rumus kadar air: $\%$ Kadar air $: \frac{b-c}{b-a} \times 100 \%$

$$
\text { Ket: } \begin{aligned}
\mathrm{a}= & \text { beratkonstancawankosong } \\
\mathrm{b}= & \text { beratcawan }+ \text { sampel sebelum } \\
& \text { dikerigkan } \\
\mathrm{c}= & \text { berat konstan cawan }+ \text { sampel } \\
& \text { setelah dikeringkan }
\end{aligned}
$$

\section{Ekstraksi Maserasi}

Alga merah ditimbang sebanyak $60 \mathrm{~g}$ dan diekstraksi secara maserasi menggunakan $300 \mathrm{~mL}$ pelarut etanol kemudian dilakukan pengocokan menggunakan shakker selama 3 jam, disaring dengan corong Buchner. Perlakuan yang sama dilakukan dengan mengunakan pelarut $n$-heksana. Masing-masing filtrat dipekatkan dengan rotary evaporator. 


\section{Penetasan Telur}

Sebanyak250 mL air laut dimasukkan dalam botol penetasan, dimasukkan 2,5 mg telur A. salina Leach. Selanjutnya diaerasi dan telur akan menetas dalam waktu \pm 48 jam dan siap digunakan sebagai target uji toksisitas.

\section{Uji Toksisitas}

Perlakuanujitoksisitasdilakukanseban yak 3 kali ulangan pada masing-masing ekstrak sampel. Botol disiapkan untuk pengujian, masing-masing ekstrak membutuhkan 5 botol dan 1 botol sebagai kontrol. Ekstrak kental etanol dan $n$ heksana ditimbang masing-masing sebanyak $100 \mathrm{mg}$ dan dilarutkan dalam masing-masing pelarutnya hingga volume $10 \mathrm{~mL}$ untuk membuat larutan stok 10.000 ppm. Dari larutan stok tersebut kemudian dipipet masing-masing sebanyak $25 \mu \mathrm{L}, 50$ $\mu \mathrm{L}, 100 \mu \mathrm{L}, 150 \mu \mathrm{Ldan} 200 \mu \mathrm{L}$, kemudian dimasukkan ke dalam labu ukur $10 \mathrm{~mL}$ dan pelarutnya diuapkan. Selanjutnya dimasukkan $100 \mu \mathrm{L}$ dimetil sulfoksida, setetes larutan ragi roti, $2 \mathrm{~mL}$ air laut, kemudian diaduk sampai ekstrak dapat larut dalam air laut. Dimasukkan 10 ekor larva udang Artemia salina Leach dan ditambahkan air laut sampai volumenya menjadi $10 \mathrm{~mL}$, sehingga konsentrasinya masing-masing larutan menjadi 25, 50, 100, 150 dan 200 ppm. Kemudian larutan dipindahkan kedalam botol vial.

Kontrol digunakan sebagai pembanding yang dibuat dengan cara yang sama kecuali penambahan ekstrak, yaitu dimasukkan $100 \mu \mathrm{L}$ dimetil sulfoksida, setetes larutan ragi roti, $2 \mathrm{~mL}$ air laut, kemudian dikocok sampai ekstrak dapat larut dalam air laut. Kemudian dimasukkan 10 ekor larva udang Artemia salina Leach dan ditambahkan air laut sampai volumenya menjadi $10 \mathrm{~mL}$. Pengamatan dilakukan setelah 24 jam terhadap kematian larva udang. (Rita dkk, 2008).

\section{Uji Fitokimia dengan Reagen}

\section{Uji Alkaloid}

Ekstrakalga merah (Eucheuma Cottonii) dimasukkan dalam tabung reaksi, ditambah $0,5 \mathrm{~mL} \mathrm{HCl} 2 \%$ dan larutan dibagi dalam dua tabung. Tabung I ditambahkan 2-3 tetes reagen Dragendorff, tabung II ditambahkan 2-3 tetes reagen Mayer. Jika tabung I terbentuk endapan jingga dan pada tabung II terbentuk endapan kekuning-kuningan menunjukkan adanya alkaloid.

\section{Uji Flavonoid}

Ekstrak

algamerah(Eucheuma cottonii) dimasukkan dalam tabung reaksi kemudian dilarutkan dalam 1-2 mL metanol panas $50 \%$. Setelah itu ditambah logam $\mathrm{Mg}$ dan 4-5 tetes $\mathrm{HCl}$ pekat. Larutan berwarna merah atau jingga yang terbentuk menunjukkan adanya flavonoid.

\section{Uji Triterpenoiddan Steroid}

Ekstrak alga merah (Eucheuma Cottonii) dimasukkan dalam tabung reaksi, dilarutkan dalam $0,5 \mathrm{~mL}$ kloroformlalu ditambah dengan $0,5 \mathrm{~mL}$ asam asetat anhidrat. Campuran ini selanjutnya ditambah dengan 1-2 mL asam sulfatpekat melalui dinding tabung tersebut. Jika hasil yang diperoleh berupa cincin kecoklatan atau violet pada perbatasan dua pelarut menunjukkan adanya triterpenoid, sedangkan jika terbentuk warna hijau kebiruan menunjukkan adanya steroid.

\section{PemisahanSenyawaAktif}

Ekstrakpelarut yang positif uji fitokimia dipisahkan golongan senyawanya menggunakan KLT Silika $\mathrm{GF}_{254}$.

\section{Analisis Data}

Data yang diperoleh dibuat dalam bentuk tabel dan grafik, kemudian dideskripsikan hasilnya. Tingkat toksisitas larva udangA. salina Leach dapat diketahui dengan melakukan uji LC50 menggunakan analisis probit pada program MINITAB 16 dengan tingkat kepercayaan $95 \%$. 
Identifikasi golongan senyawa dilakukan dengan uji fitokimia. Data dari pemisahan dianalisis secara deskriptif yaitu dengan memperhatikan pola pemisahan dan kenampakan noda pada kromatogram, dari berbagai eluen yang digunakan.

\section{HASIL DAN PEMBAHASAN Preparasi Sampel}

Sampel basah yang diperoleh dikeringkan dengan cara penjemuran selama 7 hari. Pengeringan dimaksudkan untuk mengurangi jumlah air yang terkandung pada alga, menghentikan reaksi enzimatis, dan mencegah tumbuhnya jamur sehingga dapat disimpan lebih lama dan tidak mudah rusak sehingga komposisi kimianya tidak mengalami perubahan (Baraja, 2008). Sampel alga kering berwarna coklat kehitaman.

Sampel kering dihaluskan dengan cara penggilingan karena alga kering memiliki tekstur yang keras. Setelah digiling sampel diayak, hal ini dilakukan bertujuan agar luas permukaan semakin besar sehingga interaksi zat cairan ekstraksi semakin besar. Serbuk dengan penghalusan yang tinggi kemungkinan sel-sel yang rusak juga semakin besar, sehingga mempermudah pengambilan senyawa aktif dari alga merah oleh bahan pelarut (Octavia, 2009). Serbuk alga merah yang telah dihaluskan berwarna coklat.

\section{Analisis Kadar Air}

Analisis kadar air dilakukan untuk mengetahui kandungan air yang terdapat dalam sampel. Prinsipnya adalah penentuan kadar air dengan proses penguapan air yang terdapat pada sampel menggunakan oven dengan suhu $100-105{ }^{\circ} \mathrm{C}$ hingga diperoleh berat konstan. Hasil analisis kadar air pada alga merah (Eucheuma cottonii) kering adalah $6,399 \%$.

Hasil pengukuran kadar air ini menunjukkan bahwa sampel yang dianalisis mempunyai kadar air cukup baik untuk dilakukan proses ekstraksi karena semakin rendah kadar air suatu sampel maka semakin mudah pelarut untuk mengekstrak komponen senyawa aktif. Sulistijowati (2001) menyatakan bahwa kadar air maksimum yang disyaratkan agar proses ekstraksi dapat berjalan lancar yaitu sebesar $11 \%$.

\section{EkstraksiMaserasi}

Maserasi dilakukan dengan menimbang serbuk sampel sebanyak $60 \mathrm{~g}$ kemudian direndam dalam pelarutnya yaitu etanol $96 \%$ dan $n$-heksana. Pemilihan pelarut didasarkan pada tingkat kepolarannya. Senyawa yang bersifat polar hanya dapat larut dalam pelarut polar dan semipolar, dan sebaliknya, senyawa yang bersifat nonpolar hanya dapat larut dalam pelarut nonpolar dan semi polar yang dikenal dengan hukum "likedissolvelike" (Khopkar, 1990).

Hasil proses ekstraksi dapat dilihat pada Tabel 1.

Tabel 1. Hasil Proses maserasi

\begin{tabular}{|c|c|c|c|}
\hline Pelarut & $\begin{array}{c}\text { Warna } \\
\text { filtrat }\end{array}$ & $\begin{array}{c}\text { Warnaeks } \\
\text { trakpekat }\end{array}$ & $\begin{array}{c}\text { Rend } \\
\text { emen } \\
(\mathbf{\%}) \\
(\mathbf{b} / \mathbf{b})\end{array}$ \\
\hline Etanol & Hijau & Coklat & 1,13 \\
\hline $\begin{array}{c}n- \\
\text { heksana }\end{array}$ & Kuning & $\begin{array}{c}\text { Hijau } \\
\text { kecoklatan }\end{array}$ & 0,78 \\
\hline
\end{tabular}

\section{Uji Toksisitas}

Larutan uji di ambil dari larutan stok $10.000 \mathrm{ppm}$ yaitu dengan mengambil 25 $\mu \mathrm{L}, 50 \mu \mathrm{L}, 100 \mu \mathrm{L}, 150 \mu \mathrm{L}$ dan $200 \mu \mathrm{L}$ masing-masing ekstrak kedalam labu ukur $10 \mathrm{~mL}$. Selanjutnya pelarut masing-masing ekstrak diuapkan sampai kering dalam lemari asam agar kematian larva tidak dipengaruhi oleh pelarutnya. Setelah pelarutnya menguap, ditambahkan dengan $100 \mu \mathrm{L}$ surfaktan dan $2 \mathrm{~mL}$ air laut, kemudian dilarutkan sampai ekstrak larut sempurna dengan bantuan sonikasi, surfaktan yang digunakan dalam penelitian ini adalah DMSO (dimetil-sulfoksida).

Meyer (1982) dalam Farihah (2008) melaporkan bahwa suatu ekstrak menunjukkan aktivitas ketoksikan dalam BSLT jika ekstrak dapat menyebabkan kematian $50 \%$ hewan uji pada konsentrasi 
kurang dari 1000 ppm. Pernyataan diatas menunjukkan kedua ekstrak alga merah (Eucheuma cottonii) bersifat toksik terhadap Artemiasalina karena memiliki nilai $\mathrm{LC}_{50}<1000$ ppm. Berdasarkan analisis probit kedua ekstrak, yaitu ekstrak etanol dan $n$-heksana masing-masing diperoleh nilai $\mathrm{LC}_{50}$ yaitu 58,0128 ppm dan 61,7571 ppm. Kandungan senyawa yang berpotensi dalam kedua ekstrak tanaman ini dapat diketahui berdasarkan hasil uji fitokimia.

\section{Uji Fitokimia dengan Reagen}

Uji fitokimia dilakukan terhadap golongan senyawa alkaloid, flavonoid dan triterpenoid/steroid. Kedua ekstrak etanol dan $n$-heksana memiliki sifat toksik sehingga pengujian fitokimia dilakukan terhadap kedua esktrak ini

Tabel 2. Hasil pengamatan uji fitokimia

\begin{tabular}{|l|c|c|}
\hline Golongan senyawa & $\begin{array}{c}\text { Ekstrak } \\
\text { etanol }\end{array}$ & $\begin{array}{c}\text { Ekstrak } \\
\boldsymbol{n} \text { - } \\
\text { heksana }\end{array}$ \\
\hline $\begin{array}{l}\text { Alkaloid, meliputi } \\
\text { - Reagen } \\
\text { Dragendroff } \\
\text { - Reagen Meyer }\end{array}$ & - & - \\
\hline Flavonoid & - & - \\
\hline Steroid & - & + \\
\hline Triterpenoid & + & - \\
\hline
\end{tabular}

Keterangan:

tanda+ : terkandung senyawa/terbentuk warna

tanda - : tidak terkandung senyawa/tidak terbentuk warna

Hasil identifikasi senyawa aktif berdasarkan uji fitokimia pada masingmasing ekstrak ditunjukkan adanya golongan senyawa triterpenoid pada ekstrak etanol dan steroid pada ekstrak $n$-heksana.

Ekstrak etanol E. cottonii menunjukkan adanya senyawa triterpenoid karena terbentuk cincin coklat setelah ditetesi asam sulfat pekat melalui dinding tabung reaksi (Robinson, 1995). Senyawaan triterpenoid yang memiliki gugus $-\mathrm{OH}$ menyebabkan sifatnya menjadi polar, sehingga dapat terekstrak dalam pelarut etanol (polar). Harborne (1987) menyebutkan bahwa senyawa triterpenoid dapat diekstraksi menggunakan metanol panas. Metanol bersifat polar memiliki konstanta dielektrikum 33,6, sedangkan etanol juga bersifat polar dengan konstanta dielektrikum 24,3 (Sudarmadjidkk, 2003). Berdasarkan pendekatan tingkat kepolaran kedua pelarut ini maka triterpenoid dapat terlarut dalam pelarut etanol. Anhidrida asetat akan bereaksi dengan atom $\mathrm{O}$ pada gugus $-\mathrm{OH}$ yang ada pada senyawa triterpenoid. Reaksi yang terjadi merupakan reaksi esterifikasi, dimana senyawa ester dan asam karboksilat dibentuk oleh senyawa triterpenoid dengan anhidrida asetat.

Steroid merupakan golongan lipid yang diturunkan dari senyawa jenuh yang dinamakan siklopentanoperhidrofenantrena, yang memiliki inti dengan 3 cincin sikloheksana terpadu dan 1 cincin siklopentana yang tergabung pada ujung cincin sikloheksana tersebut. Beberapa turunan steroid yang penting ialah steroid alkohol atau sterol. Steroid lain antara lain asam-asam empedu, hormon seks (androgen dan estrogen) dan hormon kortikosteroid (Poedjiadi, 1994). Senyawa steroid terdapat dalam setiap makhluk hidup. Steroid yang ditemukan dalam jaringan tumbuhan disebut fitosterol, sedangkan yang ditemukan dalam jaringan hewan disebut kolesterol. Beberapa senyawa ini jika terdapat dalam tumbuhan akan dapat berperan menjadi pelindung. Senyawa ini tidak hanya bekerja menolak beberapa serangga tetapi juga menarik beberapa serangga lain (Robinson, 1995).

\section{Uji Fitokimia dengan KLT \\ Triterpenoid}

Hasil identifikasi dengan KLT golongan senyawa triterpenoid dalam ekstrak etanol dengan eluen $n$-heksana:etil asetat (7:3) dengan pereaksi penyemprot reagenLiebermann-Burchard. 


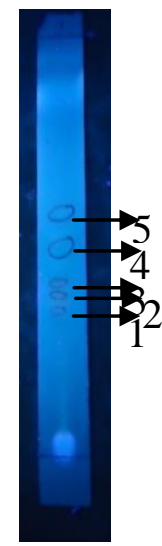

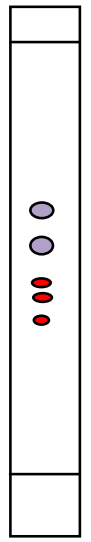

(b)

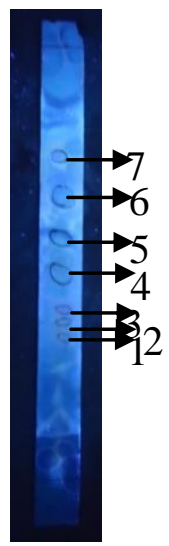

(c)

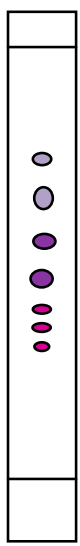

(d)
Gambar 1. Hasil KLT senyawa triterpenoid pada ekstrak etanol; (a) hasil pengamatan di bawah sinar UV pada $\lambda \quad 366 \quad \mathrm{~nm}$ sebelum disemprot reagenLiebermanBurchard; (b) ilustrasi gambar a; (c) hasil pengamatan di bawah sinar UV pada $\lambda 366 \mathrm{~nm}$ setelah disemprot reagenLiebermanBurchard; (d) ilustrasi gambar c.

Tabel 3. Hasil KLT senyawa triterpenoid pada ekstrak etanol

\begin{tabular}{|c|c|c|c|}
\hline \multirow{2}{*}{ No } & \multirow{2}{*}{$\begin{array}{c}\text { Rf tiap } \\
\text { noda }\end{array}$} & $\begin{array}{c}\text { Warna noda di bawah sinar } \\
\text { UV pada } \lambda 366 \mathrm{~nm}\end{array}$ \\
\cline { 3 - 4 } & $\begin{array}{c}\text { Sebelum } \\
\text { disemprot } \\
\text { reagen } \\
\text { Liebermann- } \\
\text { Burchard }\end{array}$ & $\begin{array}{c}\text { Setelah } \\
\text { disemprot } \\
\text { reagen } \\
\text { Liebermann- } \\
\text { Burchard }\end{array}$ \\
\hline 1 & 0,33 & Merah & $\begin{array}{c}\text { Merah } \\
\text { keunguan }\end{array}$ \\
\hline 2 & 0,36 & Merah & $\begin{array}{c}\text { Merah } \\
\text { keunguan }\end{array}$ \\
\hline 3 & 0,39 & Merah & $\begin{array}{c}\text { Merah } \\
\text { keunguan }\end{array}$ \\
\hline 4 & 0,48 & Ungu & Ungu tua \\
\hline 5 & 0,56 & Ungu & Ungu tua \\
\hline 6 & 0,65 & - & Ungu muda \\
\hline 7 & 0,74 & - & Ungu muda \\
\hline
\end{tabular}

Golongan senyawa triterpenoid hasil KLT setelah disemprot dengan reagen Lieberman-Burchard ditunjukkan dengan terbentuknya bercak noda berwarna merah ungu (violet) (Listiani dkk., 2005), ungu tua (Bawa, 2009), merah keunguan dan kecoklatan (Halimah, 2010).

\section{Steroid}

Hasil identifikasi dengan KLT golongan senyawa steroid dalam ekstrak $n$ heksana dengan eluen $n$-heksana:etil asetat (17:3) yang disemprot dengan pereaksi Lieberman-Burchardmenunjukkan terbentuknya 8 noda yang terpisah di bawah sinar UV pada panjang gelombang $366 \mathrm{~nm}$. Hasil KLT dari pemisahan steroid ekstrak kloroform ini dapat ditunjukkan pada Gambar 2 dan Tabel 4.

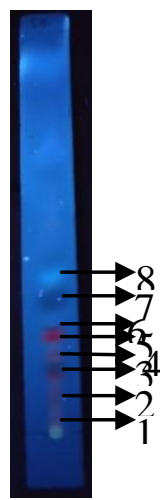

(a)

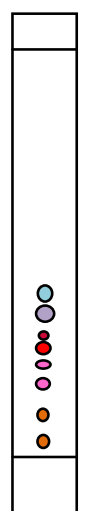

(b)

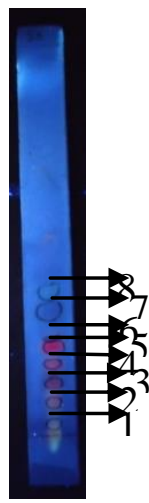

(c)

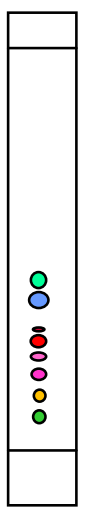

(d)
Gambar 2. Hasil KLT senyawa steroid pada ekstrak n-heksana; (a) hasil pengamatan di bawah sinar UV pada $\lambda \quad 366 \quad \mathrm{~nm}$ sebelum disemprot reagenLiebermanBurchard; (b) ilustrasi gambar a; (c) hasil pengamatan di bawah sinar UV pada $\lambda 366 \mathrm{~nm}$ setelah disemprot reagenLiebermanBurchard; (d) ilustrasi gambar c.

Tabel 4.4 Hasil KLT senyawa steroid pada ekstrak $n$-heksana

\begin{tabular}{|c|c|c|c|}
\hline \multirow{2}{*}{ No } & & \multicolumn{2}{|c|}{ Warna noda di bawah sinar } \\
\cline { 3 - 4 } & $\begin{array}{c}\text { Rf } \\
\text { tiap } \\
\text { noda }\end{array}$ & $\begin{array}{c}\text { Sebelum } \lambda 366 \mathrm{~nm} \\
\text { disemprot } \\
\text { reagen } \\
\text { Liebermann- } \\
\text { Burchard }\end{array}$ & $\begin{array}{c}\text { Setelah } \\
\text { disemprot } \\
\text { reagen } \\
\text { Liebermann- } \\
\text { Burchard }\end{array}$ \\
\hline 1 & 0,02 & Oranye & Hijau \\
\hline 2 & 0,08 & Oranye & Oranye \\
\hline 3 & 0,13 & Merah muda & Merah muda \\
\hline 4 & 0,17 & Merah muda & Merah muda \\
\hline 5 & 0,22 & Merah & Merah \\
\hline 6 & 0,23 & Merah & Merah \\
\hline 7 & 0,31 & Ungu & Ungu \\
\hline 8 & 0.36 & Biru & $\begin{array}{c}\text { Biru } \\
\text { kehijauan }\end{array}$ \\
\hline
\end{tabular}


Golongan senyawa steroid hasil KLT setelah disemprot dengan reagenLieberman-Burchard ditunjukkan dengan terbentuknya bercak noda berwarna hijau (Handayani, 2008), hijau terang sampai hijau kecoklatan (Halimah, 2010), biru (Kristanti, 2008). Dari tabel diatas diketahui bahwa ada dua bercak yang dapat diasumsikan sebagai senyawa steroid.

\section{KESIMPULAN}

1. Masing-masingekstrak alga merah (Eucheuma cottonii) memiliki tingkat toksisitas yang cukup tinggi terhadap larva udang Artemia salina Leach, ditunjukkan dengan nilai $\mathrm{LC}_{50}<1000$ ppm. Ekstrak etanol dengan nilai $\mathrm{LC}_{50}$ sebesar 58,0128 ppm dan 61,7571 ppm untuk ekstrak $n$-heksana.

2. Kandungan golongan senyawa aktif yang terkandung dalam ekstrak alga merah (E. cottonii) yaitu golongan senyawa triterpenoid dalam ekstrak etanol dan steroid dalam ekstrak $n$ heksana.

\section{DAFTAR PUSTAKA}

Baraja, M. 2008. Uji Toksisitas Ekstrak Daun Ficuselastica Noisex Blume terhadap Artemia salina Leach dan Profil Kromatografi Lapis Tipis. Skripsi Diterbitkan. Surakarta: Fakultas Farmasi Universitas Muhammadiyah Surakarta.

Bawa, IG. A. G., Putra, B. A. A., danLaila, I. R. 2007. Penentuan pH Optimum Isolasi Karaginan dari Rumput Laut Jenis Eucheuma cottonii.Jurnal Kimia 1 (1) : 15-20.

Costa, M. 2003. Potential Hazard of Hexavalent Chromate in Our Drinking Water, Toxicol. Appl. Pharmacol., 188 : 1-5.

Farihah. 2006. Uji Toksisitas Ekstrak Daun Ficusbenjamina $L$ terhadap Artemia salina Leach dan Profil Kromatografi Lapis Tipis. Skripsi Diterbitkan. Surakarta: Fakultas Farmasi Universitas Muhammadiyah Surakarta.
Halimah, N. 2010. Uji Fitokimia dan Uji Toksisitas Ekstrak Tanaman AntingAnting (Acalypha indica L.)Terhadap Larva Udang Artemia salina L. Tugas Akhir Tidak Diterbitkan. Malang: UIN Maulana Malik Ibrahim Malang.

Handayani D., N. SayutidanDachriyanus. 2008. Isolasi dan Karakterisasi Senyawa Anti bakteri Epidioksi Sterol dari Spon Laut Petrosianigrans, Asal Sumatera Barat. Prosiding Seminar Nasional Sains dan Teknologi- II 2008. Lampung: Universitas Lampung

Harborne, J.B. 1987. MetodeFitokimia. diterjemahkan oleh Kosasih Padmawinata dan Iwang Sudiro, Terbitan II, 5-9, 147-155. Bandung: Institut Teknologi Bandung

Khopkar, S.M. 1990. Konsep Dasar Kimia Analitik. Jakarta: Penerbit UI-Press.

Kristanti, A.V, Aminah, N.S, Tanjung, M., Kurniadi, B. 2008. Buku Ajar Fitokimia. Airlangga University Press. Surabaya

Listiani, L., I. FidriannydanSukrasno. 2005. Telaah Kandungan Kimia Daun Kucai (Allium schoenoprasumL., Liliaceae). Bandung: Jurnal Sekolah Farmasi ITB. http://bahanalam.fa.itb.ac.id. Diaksestanggal 25 Desember 2012.

Nurhayati, A. P. D., Nurlita A., dan Rachmat F. 2006. Uji Toksisitas Ekstrak Eucheuma alvarezii Terhadap Artemia salina Sebagai Studi Pendahuluan Potensi Antikanker. Jurnal Akta Kimindo Vol. 2 No. 1 Hal. 41-46

Octavia, D,R. 2009. Uji Aktivitas Penangkap Radikal Ekstrak Petroleum Eter, Etil Asetat dan Etanol Daun Binahong (Anredera Corfolia (Tenore) Steen) dengan metode DPPH (2,2-difenil-1- pikrihidrasil.). Skripsi Diterbitkan. Surakarta: Fakultas Farmasi Universitas Muhamadiyah

Poedjiadi, A. 1994. Dasar-Dasar Biokimia. Jakarta: UI Press 
Rita, W. S., I. W. Suirtadan A. Sabirin. 2008. Isolasi dan Identifikasi Senyawa yang Berpotensi Sebagai Antitumor pada Daging Buah Pare (Momordicacarantia L). Bukit Jimbaran: Jurusan Kimia FMIPA Universitas Udayana. Jurnal Kimia 2(1). ISSN 1907-9850: 1-6.

Robinson, T. 1995. Kandungan Senyawa Organik Tumbuhan Tinggi. Diterjemahkan oleh Prof.Dr.Kosasih Padmawinata, Bandung: ITB.
Sudarmadji, S., B. HaryonodanSuhardi.2007. Prosedur Analisa Bahan Makanan dan Pertanian. Yogyakarta: Liberty.

Sulistijowati, S dan D. Gunawan.2001. Efek Ekstrak Daun Kembang Bulan (Tithoniadifersifolia A. Gray) Terhadap Candicaalbicans Serta Profil Kromatografinya. Jakarta: Pusat Penelitian Dan Pengembangan Kesehatan. 